\title{
0 papel do Ministério Público no processo de inventário na defesa dos interesses de herdeiros incapazes e ausentes - 0 antes e 0 após a Lei № 117/2019, de 13 de Setembro: uma reflexão
}

https://doi.org/10.21814/uminho.ed.30.11

\author{
Diana Leiras \\ Professora Adjunta Convidada do \\ Instituto Politécnico do Cávado e do Ave
}

\section{Introdução}

A Lei 117/2019, de 13 de setembro, em vigor desde 1 de janeiro de 2020, veio revogar o Regime Jurídico do Processo de Inventário (RJPI), aprovado pela Lei 23/2013, de 5 de março (arts. $15^{\circ}$ e $10 .^{\circ}$ da Lei 117/2019), que atribuía competência exclusiva aos cartórios notariais para a tramitação dos processos de inventário (art. 3. ${ }^{\circ}$ do RJPI).

Por razões de ordem prática, na vigência desse Regime, a intervenção do M.P. para tutela dos interesses de herdeiros menores, maiores acompanhados e ausentes em parte incerta apenas se fazia a final, quando o processo era remetido ao tribunal judicial para efeitos de homologação da partilha (art. $66^{\circ}{ }^{\circ}$, n. ${ }^{\circ} 2$, do RJPI). No novo regime do inventário, a matéria da competência para o tratamento dos inventários foi novamente modificada, e com implicações no que respeita ao exercício da atribuição do M.P. de representação processual de tais herdeiros.

Com este texto, procuramos contribuir para a reflexão sobre se os interesses de herdeiros incapazes e ausentes em parte incerta estavam, nos regimes do inventário pretéritos, e estão, no regime do inventário atual, devidamente acautelados pelo órgão do Estado a quem está cometida a respetiva representação processual.

\section{Breves notas sobre o atual enquadramento do processo de inventário}

Até à entrada em vigor da Lei n. ${ }^{\circ}$ 23/2013, de 5 de março (em 2 de setembro de 2013, cfr. art. $8 .^{\circ}$ dessa Lei), que aprovou em anexo o Regime Jurídico do Processo de Inventário (RJPI), o processo de inventário encontrava-se regulado no Código de Processo Civil de 1961 (CPC/61), e enquanto assim acontecia, a tramitação dos processos de inventário cabia, em exclusivo, aos tribunais judiciais (arts. $1326 .{ }^{\circ}$ a $1406 .{ }^{\circ}$ ). 
A morosidade na tramitação e resolução dos inventários nos tribunais judiciais esteve na génese da aprovação do RJPI, que desjudicializou estes processos mediante a atribuição aos notários de competência exclusiva para a respetiva tramitação ${ }^{1}$. À luz desse Regime, ao juiz (apenas) competia aferir da legalidade dos atos praticados, da legalidade e da regularidade do processo, proferindo, a final, a sentença homologatória da partilha (cfr. arts. $3 .^{\circ}$ e $66 .^{\circ}$ do RJPI).

Ressalvada a modificação relativa à competência para o tratamento dos atos e termos do processo, e algumas particularidades que foram introduzidas, a maioria delas decorrentes daquela modificação, o RJPI introduziu a mesma tramitação que estava prevista no regime do inventário que constava do CPC/61. Como explicitaremos adiante, por respeitar ao tema de que trata este texto, o afastamento dos inventários dos tribunais judiciais teve necessárias implicações no exercício da atribuição do M.P. de representação dos incapazes e ausentes que sejam interessados diretos no inventário.

A desjudicialização dos processos de inventário perspetivava boas intenções, mas, na prática, ficou aquém das expetativas criadas. Na vigência do RJPI, constatou-se que a solução encontrada pelo legislador de substituição do juiz pelo notário na realização das diligências destes processos não foi a mais adequada. O RJPI não só não logrou alcançar os resultados de celeridade, eficiência e eficácia a que se propôs, como foi causa da instalação do caos que se gerou em relação a estes processos, com inerente prejuízo para os direitos dos interessados.

Foi nesse panorama que foi aprovada a Lei n. ${ }^{\circ} 117 / 2019$, de 13 de setembro, que veio reconstruir e recodificar o processo de inventário no atual Código de Processo Civil (arts. $1082 .^{\circ}$ a $1135 .{ }^{\circ 2}$ ), repristinando a competência dos tribunais judiciais para a realização de partilhas litigiosas. Ainda que estabelecendo a repartição de competências entre os tribunais judiciais e os cartórios notariais, consagrando, portanto, o inventário judicial e o inventário notarial, essa Lei veio prever casos em que o processo tem necessariamente de ser instaurado no tribunal judicial, e, fora esses casos, quando o inventário tenha sido requerido num cartório notarial, a possibilidade, observados certos pressupostos, de o processo ser remetido para o tribunal judicial competente (cfr. art. 1083. ${ }^{\circ}$ ). Desta feita, do novo regime do inventário resulta uma competência primacial dos tribunais judiciais para o tratamento dos inventários, consagrando a desjudicialização destes processos, que outrora foi imperativa, num segundo plano.

\footnotetext{
1 A desjudicialização destes processos já havia sido consagrada no Regime Jurídico do Processo de Inventário aprovado pela Lei n. ${ }^{\circ} 29 / 2009$, de 29/06, no qual se incumbia aos notários, e também os serviços de registo (a definir por portaria), as funções de tramitação do processo de inventário. Porém, face às dificuldades que se anteviram na aplicação prática da desjudicialização total que esse regime consagrava, o mesmo não chegou a produzir efeitos Cfr. a Proposta de Lei n. ${ }^{\circ} 105-\mathrm{XII}$ - Proposta de Lei que deu origem à Lei n. ${ }^{\circ}$ 23/2013, de 05/03, disponível em: https://www.parlamento.pt/ActividadeParlamentar/Paginas/Detalhelniciativa.aspx?BID=37329 (acesso em 9/5/2021).

2 Pertencem ao Código de Processo Civil aprovado pela Lei n. ${ }^{\circ} 41 / 2013$, de 26 de junho na sua redação atual (conferida pela Lei n. ${ }^{\circ} 117 / 2019$, de 13 de setembro) todos os preceitos indicados sem menção da respetiva fonte.
} 


\section{A atuação do M.P. em representação de herdeiros incapazes e ausentes na vigência do RJPI}

Logo no início da vigência do RJPI, pelo facto de os inventários serem tramitados nos cartórios notariais e não nos tribunais judiciais, surgiram dúvidas quanto à intervenção do M.P. nestes processos para defesa dos interesses de herdeiros incapazes e ausentes.

$\mathrm{Na}$ altura, ainda se encontrava em vigor o anterior Estatuto do Ministério Público, aprovado pela Lei n. ${ }^{\circ} 47 / 86$, de 15 de outubro, que tal como o atual, aprovado pela Lei n. ${ }^{\circ}$ 68/2019, de 27 de agosto, estabelecia, em concretização do art. 209. ${ }^{\circ}$, n. ${ }^{\circ} 1$, da CRP, a competência do M.P. para representar os incapazes e ausentes (arts. $1 .^{\circ} \mathrm{e}$ 3. ${ }^{\circ},{ }^{\circ}{ }^{\circ} 1$, al. a)), pressupondo a sua intervenção, seja a título principal ou acessório, a pendência de uma causa em juízo nos tribunais estaduais, (tribunais judiciais ou tribunais administrativos e fiscais) (arts. $5^{\circ}$, n. $^{\circ} 1$, al. c), e n. ${ }^{\circ} 4$, e $6 .^{\circ}$ ).

Neste âmbito, levantou-se também a questão sobre a legitimidade do M.P. para requerer inventário no caso em que a herança se deferia a incapaz ou ausente. 0 RJPI não continha uma norma análoga à al. b) do n. 1 do art. $1327 .^{\circ}$ do CPC/61 que expressamente estipulava essa legitimidade, e segundo o art. $4 .^{\circ}$, n. $^{\circ} 1$, do RJPI, apenas tinham legitimidade para requerer os "interessados diretos na partilha” (al. a), e "quem exerce as responsabilidades parentais, ao tutor ou ao curador, consoante os casos, quando a herança seja deferida a incapazes ou ausentes em parte incerta" (al. b)). 0 problema residia essencialmente na articulação do regime processual com o disposto no art. $2102 .^{\circ}$, n. $^{\circ} 2$, do Código Civil, do qual resulta que a partilha se realiza por inventário "quando o Ministério Público entenda que o interesse do incapaz a quem a herança é deferida implica aceitação beneficiária" (al. b)), e "nos casos em que algum dos herdeiros não possa, por motivo de ausência em parte incerta ou de incapacidade de facto permanente, intervir em partilha realizada por acordo",

Apesar do silêncio do legislador quanto à legitimidade para requerer do M.P., o mesmo já não ocorria em relação à legitimidade para intervir, a qual decorria dos arts. $17 .^{\circ},{ }^{\circ} 1$ e $66^{\circ}$, n. ${ }^{\circ} 2$, RJPI.

Apesar de alguma doutrina resistir a tais orientações, a verdade é que a letra da lei evidenciava que, sendo a herança deferida a tais interessados, o M.P. não tinha legitimidade para intervir no processo enquanto o mesmo se encontrava a correr termos no cartório notarial e também não tinha legitimidade para requerer.

A intervenção do M.P. junto dos cartórios notariais foi expressamente rejeitada no Parecer n. ${ }^{\circ}$ 5/2014, da Procuradoria Geral da República, publicado em Diário da República, 2. ${ }^{a}$ série, de 30 de junho de 2014, e, no seguimento do mesmo, na Diretiva n. ${ }^{\circ}$ 3/2014, também da PGR, tendo a questão ficado clarificada para bem da certeza e segurança jurídicas, pelo menos. Portanto, na vigência do RJPI, contrariamente ao que sucedia no âmbito do regime do inventário que constava do CPC/61, em consequência da falta de competência do M.P. para atuar no âmbito dos cartórios notariais, 
estava prejudicada a possibilidade de decorrer perante notário qualquer inventário em que o M.P. figurasse como requerente, e, na pendência do inventário, este órgão do Estado estava impedido de tutelar de modo próximo os interesses dos incapazes e ausentes, os quais ficavam à mercê da atuação dos seus representantes legais.

A intervenção do M.P. fazia-se a final no momento em que o processo ingressava em juízo para que fosse proferida a decisão homologatória da partilha. O M.P. tinha a função de examinar toda a tramitação processual para determinar se a legalidade foi respeitada e se os interesses dos incapazes e ausentes foram devidamente respeitados, e o dever de promover ou dizer o que se the oferecesse e requerer a não homologação da partilha caso concluísse que a atuação dos representantes legais desses interessados tinha sido deficiente (art. $66^{\circ}$, n. $^{\circ} 2$, do RJPI).

Sucede que esse exercício da competência de representação de tais interessados fora do processo de inventário não estava em consonância com o disposto no E.M.P., e podia não assegurar as mesmas garantias jurisdicionais para os interessados em causa.

\section{A restauração da legitimidade do M.P. para intervir no processo de inventário na defesa dos interesses de herdeiros incapazes e ausentes pela Lei n. $-117 / 2019$}

No regime atual do inventário, que foi reintroduzido no Código de Processo Civil pela Lei n. ${ }^{\circ} 117 / 2019$, nos casos em que a herança é deferida a incapazes ou ausentes, o processo de inventário é da competência exclusiva dos tribunais judiciais, não tendo, portanto, o requerente a opção de requerer inventário notarial.

Efetivamente, nos termos do art. $1083 .^{\circ}$, n. $^{\circ} 1$, al. a), o inventário tem de ser requerido no tribunal judicial nos casos previstos nas alíneas b) e c) do n. 2 do Código Civil, os quais como já referimos estão relacionados com a necessidade de aceitação beneficiária da herança pelo herdeiro incapaz ou ausente e com a impossibilidade de a partilha se realizar por acordo no caso de herdeiros se encontrarem ausentes ou em situação de incapacidade de facto permanente. Ademais, da alínea c) do referido preceito (art. $1083 .^{\circ}, \mathrm{n}^{\circ} 1$ ), resulta que qualquer inventário em que seja requerente $\mathrm{o}$ M.P. tem de ser requerido no tribunal judicial.

Nessa sequência, a Lei n. ${ }^{\circ}$ 117/2019 veio restaurar a legitimidade do M.P. para requerer e para intervir, a título principal, em todos os atos e termos do processo quando a herança seja deferida a interessados diretos que sejam menores, maiores acompanhados ou ausentes (art. 1085. ${ }^{\circ}$, n. $^{\circ} 1$, al. b)), estando, portanto, hoje, estabelecida de forma diversa da que resultava do RJPI, e de forma similar à que constava do CPC/61, a competência do M.P. de tutela dos direitos desses interessados, em obediência ao disposto no art. $219 .^{\circ}$, n. $^{\circ} 1$ e no E.M.P. aprovado pela Lei n. ${ }^{\circ}$ 68/2019, de 27/08 (arts. $2 .^{\circ}$ e $4 .^{\circ}$, n. ${ }^{\circ} 1$, al. a), $8 .^{\circ},{ }^{\circ}{ }^{\circ} 1$, al. c), e 3, e $\left.10 .{ }^{\circ}\right)$. 
O M.P., quando tenha legitimidade como parte principal, intervém no inventário logo após ser proferido despacho liminar que admita o prosseguimento do processo (arts. $1100 .^{\circ}$, em especial n. ${ }^{\circ} 1$, al. c)), podendo após a sua citação exercer as faculdades previstas no $n .{ }^{\circ} 1$ do art. $1104 .^{\circ}$. A sua legitimidade aparece ainda referenciada numa série de outros preceitos legais, que respeitam a diferentes atos e termos do processo: 0 art. $1106 .^{\circ},{ }^{\circ}{ }^{\circ}$ 2, que determina que o M.P. pode opor-se ao reconhecimento vinculante das dívidas estabelecido no n. ${ }^{\circ} 1$ do mesmo artigo, para os interessados menores, maiores acompanhados ou ausentes; o art. $1110 .^{\circ}, \mathrm{n} .{ }^{\circ} 1$, al. b), que dispõe sobre a notificação do M.P. para propor a forma da partilha; o art. $1111 .^{\circ}$, n. $^{\circ}$ 2, que exige a concordância do M.P. para a realização da composição dos quinhões por acordo unanime dos interessados; e art. $1120 .^{\circ}$, n. ${ }^{\circ} 1$, quanto à notificação do M.P. para apresentar proposta de mapa da partilha.

A opção do legislador de atribuir competência exclusiva aos tribunais judiciais para a tramitação de inventários em que sejam interessados diretos menores, maiores acompanhados ou ausentes incidiu inclusivamente sobre os processos que à data da entrada em vigor da Lei n. ${ }^{\circ} 117 / 2019$ (1 de janeiro de 2020, cfr. art. $15 .^{\circ}$ desta Lei) estavam pendentes. 0 legislador ordenou a remessa oficiosa desses processos pelo notário ao tribunal judicial competente, e com isso a submissão da tramitação subsequente do processo remetido ao regime estabelecido para o inventário judicial no Código de Processo Civil, que por regra, só é aplicada aos processos novos (arts. $11 .^{\circ}, 12 .^{\circ}$, n. ${ }^{\circ}$ 1, e $13 .^{\circ}$ da Lei n. ${ }^{\circ} 117 / 2019$ ). Portanto, em relação a esses inventários a remessa do processo a juízo foi estabelecida como uma obrigação do notário e não como uma opção de qualquer interessado direto, solução que, por sua vez, foi adotada quanto aos processos que se encontravam suspensos ao abrigo do art. $16 .^{\circ}$ do RJPI e que estavam parados, sem realização de diligências úteis, há mais de seis meses (art. 13. ${ }^{\circ}$, n. ${ }^{\circ}$ 2, da Lei n. ${ }^{\circ} 117 / 2019$ ).

Neste âmbito, chamamos à colação para o recente Acórdão do Tribunal da Relação de Lisboa, de 25/02/2021, processo n. ${ }^{\circ}$ 594/20-4T8PDL-B.L1-6, que, em relação a um inventário que transitou oficiosamente do cartório notarial para o tribunal atenta a existência de um interessado menor, decidiu do seguinte modo: "Encontrando-se o processo numa fase inicial do seu desenvolvimento quando transitou para o tribunal judicial - decorrido o prazo da oposição ou impugnação posterior à citação dos interessados - a intervenção do Ministério Público não deve ficar subordinada à conduta omissiva do representante legal do menor no que toca à reclamação contra a relação de bens".

Destarte, visando pôr fim ao défice que o inventário notarial implicava para a tutela dos interesses de herdeiros incapazes e ausentes, a Lei assegura que todos os inventários em que existam tais interessados, mesmo os que tenham sido instaurados na vigência do RJPI, são tramitados no tribunal judicial, portanto, sob a alçada de um juiz, e com intervenção principal do M.P., que é citado para todos os atos e termos do processo. 


\section{Conclusão}

O novo regime do inventário atribui competência exclusiva aos tribunais judiciais para o tratamento do processo de inventário quando sejam interessados diretos menores, maiores acompanhados ou ausentes, restabelecendo a atuação do M.P. em juízo na defesa imediata e efetiva dos direitos desses interessados, tal como acontecia na vigência do anterior Código de Processo Civil.

O facto de o legislador ter ordenado a transição oficiosa dos processos pendentes nos cartórios notariais aos tribunais competentes quando existam interessados diretos em tais condições de incapacidade ou ausência, constitui, para nós, um assumir de que a tramitação desses processos nos cartórios notariais sem a intervenção do M.P. não constituía garantia de que efetivamente os direitos desses interessados estavam acautelados no regime anterior.

Por último, salientamos que o fim da desjudicialização destes processos e a atuação do M.P. na pendência do processo favorecem a utilidade dos atos processuais ao suprimirem a hipótese, que o RJPI admitia, de não homologação da partilha pelo facto de na pendência do processo não terem sido devidamente salvaguardados os interesses dos incapazes e ausentes pelos respetivos representantes legais. 
Processo de inventário. Reflexões sobre o novo regime jurídico - Lei n. ${ }^{\circ}$ 23/2013, de 5 de março, Coimbra Almedina, 2014.

CÂMARA, Carla (e outros), Regime Jurídico do Processo de Inventário anotado, 2. a edição, Coimbra, Almedina, 2013.

CARDOSO, Augusto Lopes, Partilhas judiciais, volume I, 6. ${ }^{a}$ edição, Coimbra, Almedina, 2015;

CARDOSO, João António Lopes, e CARDOSO, Augusto Lopes, Partilhas judiciais, vol. I, 5. a edição, Coimbra, Almedina, 2006;

GERALDES, António Santos Abrantes (e outros), Código de Processo Civil anotado. Processo de execução, processos especiais e processo de inventário judicial. Vol. II, Coimbra, Almedina, 2020;

LEIRAS, Diana, Um Olhar sobre... as Principais Alterações ao Regime do Processo de Inventário - Lei n. ${ }^{\circ}$ 23/2013, de 5 de março. in "Solicitadoria e Ação Executiva - Estudos" \# 2, Câmara dos Solicitadores, outubro 2014, pp. 17-29.

PAIVA, Eduardo Sousa, e CABRITA, Helena, Manual do processo de inventário à luz do novo regime, Coimbra, Coimbra Editora, 2013.

PAIVA, Eduardo Sousa, O novo processo de inventário. Traves mestras da reforma. Tutela Jurisdicional.Algumas questões, in “Julgar Online”, setembro/2014, N. ${ }^{\circ} 24$, disponível na Internet em http://julgar.pt/wp-content/ uploads/2014/09/06-Eduardo-Paiva-Traves-Mestras-reforma-invent\%C3\%A1rio.pdf;

RAMIÃO, Tomé D`Almeida, Novo regime do processo de inventário judicial e notarial anotado e comentado, Lisboa, Quid luris, 2020;

REGO, Carlos Lopes do, A recapitulação do inventário, in “Julgar Online”, dezembro/2019, N. 15, disponível na internet em http://julgar.pt/wp-content/uploads/2019/12/20191216-ARTIGO-JULGAR-ARecapitula\%C3\%A7\%C3\%A3o-do-Invent\%C3\%A1rio-revis\%C3\%A3o-Carlos-Lopes-do-Rego-v5.pdf;

SOUSA, Miguel Teixeira de (e outros), O novo regime do processo de inventário e outras alterações na legislação processual civil, Coimbra, Almedina, 2020. 